\section{LOCAL WISDOM, ENVIRONMENTAL PROTECTION AND COMMUNITY DEVELOPMENT: THE CLAM FARMERS IN TAMBON BANGKHUNSAI, PHETCHABURI PROVINCE, THAILAND ${ }^{1}$}

\section{Kamonthip Kongprasertamorn ${ }^{2}$}

\begin{abstract}
The present article is a study of the use of the People Research and Development Method as a means of promoting local wisdom, environmental protection, and community development in Tambon Bangkhunsai, Phetchaburi Province, Thailand. This method allowed the community to do their own research and to utilize their local wisdom as a form of untapped capital on which self-reliance can be built. Research findings indicated that the People Research and Development method could stimulate local

\footnotetext{
${ }^{1}$ This essay is part of the Ph.D. research entitled 'The Community Learning Process on Sustainable Mangrove Forest Development: A Case Study in Tambon Bangkhunsai, Amphur Banlaem, Phetchaburi Province,' under the supervision of Dr. Seri Phongphit. The research is sponsored by the Royal Golden Jubilee Project of the Thailand Research Fund. The author would like to express her thanks to Dr. Michael Howard for his comments on this essay.

${ }^{2}$ Environmental Official, Office of Natural Resources and Environmental Policy and Planning, Ministry of Natural Resources and Environment
}

wisdom to protect the environmental and develop the community in a number of ways. In particular, the local fishermen employed their local wisdom to collect clams and shellfish. They were able to make their own gear in such a way as not to destroy the natural resources and to ensure the preservation of the natural resources for a long time. Local wisdom was also used in the formation of community development projects such as an eco-tourism group and a processed seafood group. It is anticipated that these projects will lead to sustainable resources management.

\section{Introduction}

In the past, Thailand had abundant and diverse natural resources. To live in harmony with the environment, local people used the wisdom accumulated by their ancestors to manage natural resources. The utilization of local wisdom can be seen in terms of their daily activities, such as work and festivals.

In 1961, Thailand started the first National Development Plan. It could be said that this plan mainly concentrated on economic development without regard to the destruction of natural resources and the environment. Natural resources were heavily used as raw materials for the production of goods and for services that provided the highest financial return. However, as a result of the plan, the devastation of natural resources such as forests and mineral resources increased substantially.

Unfortunately, some resources, such as mineral resources, are non-renewable. Others, e.g., forests, take a long time to replenish themselves. As a consequence, the stock of natural resources available for 
the country's economic development has decreased significantly. Such a situation has led to alterations in the concepts underlying the eighth and the ninth National Development Plans. According to the Brundtland Commission's report (1987), It was at this point that the integration of economic development, human well-being, and environmental development began to be promoted. However, the present study argues that the ideas underlying sustainable development are not new to Thailand. On the contrary, the application of traditions of local wisdom to manage natural resources has enabled people in Thailand to live in harmony with nature for a long time.

\section{The Study}

The present study aims to contribute to and enhance knowledge about the relationship between local wisdom concerning environmental protection and community development. To examine both local wisdom regarding environmental protection and community development, the research on which the present paper is based focused on the clam farmers in Tambon Bangkhunsai, Phetchaburi Province, Thailand. I employed the People Research and Development (PR\&D) method formulated in 1988 by Dr. Seri Phongphit and others on the basis of their experience in development work in rural areas with the Thai Village Foundation since 1985 (Phongphit and Nantasuwan, 2002a, 2002b). This method allowed the community to be engaged and to learn from their experiences. More importantly, the PR\&D method seeks to enhance the potential of the community to concentrate on their local wisdom as a form of untapped "capital" on which self-reliance can be built.
Local wisdom refers to the knowledge that comes from the community's experiences and the accumulation of local knowledge. Local wisdom is found in societies, communities, and individuals. Phongphit and Nantasuwan (2002a, 2002b; see also $\mathrm{Na}$ Talang, 2001) have described local wisdom as knowledge based on the experiences of people that is handed down over the generations, sometimes by those who may be seen as village philosophers. This knowledge is used as a guideline for people's daily activities in relations with their families, their neighbors, and other people in the village and with their surroundings. The central idea, Phongphit and Nantasuwan argue, is that villagers must respect their ancestors, spiritual practices, and nature. They conclude that the characteristics of local wisdom can be explained as follows: (1) local wisdom must incorporate knowledge of virtue that teaches people about ethics and moral values; (2) local wisdom must teach people to love nature, not to destroy it; and (3) local wisdom must come from the older members of the community. They also explain that local wisdom is presented in many forms, through people's thoughts, occupations, ways of living, and social values. The problem is that local wisdom usually is not officially published and promoted. As a consequence, it is difficult for the public to learn about and use this kind of knowledge.

The actual research based on the PR\&D method in Tambon Bangkhunsai involved a number of activities. A meeting was held between the researcher and people from the communities to inform participants about the objectives, processes, expected results, and benefits of the project. The main idea underlying this meeting was to encourage local people to conduct their own research in relation to the project. Local people 
were then asked to collect and analyze data themselves. Community learning through data analysis is central to this procedure. Through such analysis, both problems in the community and the causes of these problems were to be identified and discussed.

Local people of Tambon Bangkhunsai subsequently collected data relevant to the problems they had identified. They found that their daily income depended mainly on the fertility of the mangrove forest. As the relationship between the mangrove forest and income became clear, they then sought to find the best ways to protect this natural resource.

A visit was arranged for the people of Tambon Bangkhunsai to Tambon Kaowkram, Krabi Province. The people of Tambon Kaowkram had used the PR\&D method to develop a community plan in 2000. Many activities from this plan had been successfully implemented. They had formed an eco-tourism group and a food handler's group, and a savings fund group had created a savings bank. The visit to Tambon Kaowkram was intended to allow the people of Bangkhunsai to see what had been accomplished and to hold discussions with the people of Kaowkram in order to see what lessons might be useful, not simply to copy. They learned about many of the experiences of the people of Kaowkram that they were able to apply to their own plan.

The people of Bangkhunsai then began to draft their community plans by analyzing the data they had collected in relation to their needs and their resources. Community meetings were held throughout the planning process to discuss and debate the evolving plans. These meetings helped to ensure that members of the community understood the plans and that they were directly involved in formulating and implementing them. The plans were monitored, and they were evaluated one to two years after being implemented.

\section{Local Wisdom at Tambon Bangkhunsai: A Case Study}

Tambon Bangkhunsai is in Ban Laem District, which is located in the coastal area near the Phetchaburi River delta in the east of Phetchaburi Province. The coast in this region consists largely of mudflats. The area stretches for 9 kilometers along the seashore and 3 kilometers inland. The total area is 27 square kilometers. There is mangrove forest and flat land inland from the mudflats.

In 2002, Tambon Bangkhunsai had a total of 1,362 , with a population of 7,326 consisting of 3,518 males and 4,308 females. Details of the number of households and the number of people in each mooban 'village' in 2002 is presented in table 1 . The average annual income for people in Tambon Bangkhunsai in 2002 was 21,185 baht per person (Tambon Bangkhunsai Subdistrict Administration Organization, 2002). 
Table 1: Number of Households and Number of People in each Mooban in 2002

\begin{tabular}{|c|c|c|c|c|}
\hline \multirow{2}{*}{ Moo } & \multirow{2}{*}{$\begin{array}{c}\text { Number of } \\
n\end{array}$} & \multicolumn{3}{|c|}{ Population } \\
\cline { 3 - 5 } & Households & Male & Female & Total \\
\hline 1 & 79 & 223 & 248 & 471 \\
\hline 2 & 133 & 273 & 350 & 623 \\
\hline 3 & 140 & 355 & 390 & 745 \\
\hline 4 & 184 & 485 & 481 & 966 \\
\hline 5 & 167 & 397 & 418 & 815 \\
\hline 6 & 103 & 245 & 254 & 499 \\
\hline 7 & 128 & 359 & 414 & 773 \\
\hline 8 & 114 & 376 & 428 & 804 \\
\hline 9 & 113 & 316 & 331 & 647 \\
\hline 10 & 149 & 355 & 379 & 734 \\
\hline 11 & 52 & 134 & 119 & 253 \\
\hline Total & 1,362 & 3,518 & 3,812 & 7,330 \\
\hline
\end{tabular}

[Source : Tambon Bangkhunsai Subdistrict Administration Organization, 2002.]

There are people form many ethnic backgrounds in this area, including Chinese, Moslem Malays, Laotian, and Thai. Each ethnic group is residentially distinct. The people who came from China are predominantly fishers. They located their houses near the seashore, in what are now Moo 1, Moo 2, and Moo 3. The Malays, who come from Indonesia are also mainly shellfish collectors and fishers, and they settled in what is now Moo 4. The people from Laos are farmers. They built their houses farther inland, near land that was suitable for cultivation. Today they occupy Moo 5, Moo 6, and Moo 7. The Thai people came from nearby and are employed both as farmers and as shellfish collectors and fishers. They currently live in Moo 8, Moo 9, Moo 10, and Moo 11.

The rate of emigration from this tambon is relatively low because local residents can earn enough money for their families from the area's abundant resources. Most people stop schooling when they complete prathom 6 (grade 6) and begin working collecting clams or fishings or farming.

As noted above, the landscape of Tambon Bangkhunsai can be divided into two parts, namely coastal mudflats and an inland flat area. The mudflats supply very important food sources to small animals and are the biggest natural grounds for clams in Thailand. The mudflats lie within the area of six mooban: Moo 1, Moo 2, Moo 3, Moo 4, Moo 8, and Moo 10. Most of the people in these communities earn their living collecting clams and fishing. The wide plain that lies inland is suitable for agriculture. It includes five mooban: Moo 5, Moo 6, Moo 7, Moo 9, and Moo 11. Although most of the people in these communities are farmers, they also often catch fish and collect clams for daily consumption and for commercial purposes.

The main area for collecting clams is in and around the mangrove forest that is located three kilometers from the seashore. The people of Tambon Bangkhunsai can collect clams from the mangrove forest all year long. There are many clams from October to December. In addition, undulated surf clams can be found from January to March, and wedge shell or bean 
clams are easily caught from March to July.

Problems began to emerge in regard to collecting clams in 1991, when commercial fishing boats came into the area. The fishing implements used by these boats caught all sizes of clams and other shellfish. The methods they employed also caused water pollution, turbidity, and sedimentation that resulted in a decrease in seabed nutrients. The loss of nutrients lead to reduction of suitable feeding grounds for aquatic animals. As a result of the alteration of the environment, the number of aquatic animals such as clams, mussels, and other shellfish, was substantially reduced. The situation deteriorated to the point where until there were no clams or other shellfish left to be harvested. It can be said that the mangrove ecosystem had been completely destroyed by commercial fishing and that this directly affected the local clam gatherers. Their incomes were reduced and were no longer sufficient to support their families. In order to survive, most of the young men and women left their homes to search for employment in Bangkok and elsewhere. Only old people and children remained in the villages. Social problems also began to occur within Tambon Bangkhunsai.

Reacting to these environmental problems, Tambon Bangkhunsai's leaders, including the kamnan 'head of the tambon', the phuyaiban 'heads of the mooban', and other people, set up the Coastal Resources Conservation Group to protect their coastal resources in 1992. The main objective underlying the establishment of the Coastal Resources Conservation Group was to stop commercial fishing boats from invading the fishing and clamming grounds and thus prevent further destruction of the ecosystem. The first step taken by this group was to send a petition to the Governor of Phetchaburi Province. The Governor responded to the petition by holding a meeting with members of the Coastal Resources Conservation Group, the commercial fishing boat groups, and local government officials. As a result of the meeting, commercial fishing boats were no longer allowed to catch fish within three kilometers of the shore.

Despite the ban, commercial fishing boats continued to fish in the area, mainly because there were not enough government officials to enforce the ban. To solve this problem, the Coastal Resources Conservation Group decided to take matters into their own hands by setting up a coast guard to protect the seashore and to keep the commercial fishing boats from entering the protected area. Members of the group used their own time, money, and other resources to protect their natural resources. Other local people also donated their money to this group to help pay for fuel, rental boats, and food, in order to help members of the community survive in the face of the encroachment of commercial fishing boats. Through these efforts the Coastal Resources Conservation Group succeeded in preventing the commercial fishing boats from entering the protected area. With these boats gone the ecosystem has gradually returned to its previous fertility, aquatic animals can once more be found in the area, some pf the local people who had moved away from the villages in search of employment came back to their families and started collecting clams and fishing again. 


\section{Local Wisdom in Tambon Bangkhunsai}

In this section I wish to examine how the people of Tambon Bangkhunsai have employed their local wisdom to protect their natural resources and the environment and to develop their community.

There are two types of local wisdom in Tambon Bangkhunsai that are relevant to the present discussion: (1) beliefs related to local practices for collecting shellfish and (2) other aspects of their culture and beliefs.

The present study found that the cycle of local shellfish collection is simple. Shellfish collectors use local implements to collect clams and other shellfish. These implements are not expensive, and shellfish collectors can easily build these themselves. To catch crabs, fish, and other sea-life beyond three kilometers from the shore, fishers must accumulate enough money to build boats. Along with boats, they require additional implements to catch crabs and fish in the deep sea.

The people of Tambon Bangkhunsai realize the significance of natural resources in enabling them to collect clams and other shellfish. Unlike commercial fishers from elsewhere who were fishing in the area, local fishers from Tambon Bangkhunsai realize that it is very important to protect the local environment in order to ensure that there are sustainable shellfish resources to provide food and income for the community. If the resources are destroyed, they will face difficulties. For local villagers, such resources mean life. Therefore they accept the local rule not to use commercial fishing implements in this area. They understand the relationship between mangrove ecology and the shellfish balance.

The villagers' attention to sustaining local resources can be witnessed in the history of their use of an implement called a cha nor to collect clams. The cha nor is triangle-shaped with a mouth about 20-30 $\mathrm{cm}$ wide. A sack about $30-50 \mathrm{~cm}$ deep is placed around the mouth. The problem created by use of this implement was that all sizes of clam were caught by the cha nor. However, only large clams were kept; the small ones were discarded and died immediately. Local people came to realize that using the cha nor contributed to the destruction of aquatic life, such as clams, and decided to stop using them, choosing to use their hands instead.

The traditional means of collecting clams employs a wooden sled that is about $30 \mathrm{~cm}$ tall. The center of the sled is made of a hardwood board that is about $2.5-4.0 \mathrm{~cm}$ thick, $20-25 \mathrm{~cm}$ wide, and $100-120 \mathrm{~cm}$ long. The front of the board is shaped like a ski, allowing it to slide on the surface of the mudflats easily. The sled is taken onto the mudflats when the tide is low. To move over the muddy surface, the operator puts one leg on the wooden board and pushes in the mud with the other leg. In contrast to the cha nor, with a sled a person uses both hands to collect only adult clams and other adult shellfish and the small ones are left behind to grow up. The adult shellfish are kept in a sack, and seawater is used to clean mud from the shell. The shellfish are put into pots when the sack is full. People stop collecting clams and shellfish when the sea level begins to rise. The rising tide helps the collectors move inshore easily. Collecting lasts for approximately five to six hours between the high and low tides. It can be 
said that this practice demonstrates a wise use of natural resources by employing implements created by local wisdom, because this method enables people to collect clams and other shellfish in a sustainable manner.

Local wisdom is also used for fishing. Fishers know the character of the winds and tides in each season as these conditions relate to particular fishery products. Such local knowledge enables them to know where to fish and what they can catch in each season. It allows them to decide on the most appropriate fishing method and fishing gear to suit each the type of fishery product.

In addition to collecting and catching seafood products, local people also know how to preserve these products for their own consumption and for purposes of increasing their value. One traditional method is using salt to preserve clams. They clean the clams and put them into sea salt for 24 hours. This process preserves clams for three days. Another means of preservation involves taking the clams out of their shells and drying them in the sun for one day. This method preserves dried surf clams for one year.

Although the people of Tambon Bangkhunsai belong to different ethnic groups, relations between these groups are harmonious. This may in large part be attributed to the fact that there are sufficient and varied resources available in the area, so people don't need to struggle and compete with one another. The harmony among the ethnic groups in this area is revealed in the ways in which they use their wisdom to live together peacefully and to respect the natural resources. It was also evident when they worked together to drive the invading commercial fishing boats out of the area.

Community harmony is likewise demonstrated in village festivals, for example, in the Boon Tai Kan ceremony in Moo 3. In this ceremony, villagers pray for God to protect them and their families. This festival is held on the third day after Songkran. Local people in the village build small wooden boats, and every family prepares dolls representing the members of the family and their pet animals, which are then placed in the wooden boats along with rice and other foods, flowers, money, water, and other items. On the morning of the ceremony day, after the monks pray, family members give food to the monks; then they eat the food that is left over together. After eating, families take their wooden boats to the sea and launch them. They believe that this traditional practice will help them to rid their lives of bad things and bring them luck. In Moo 5 and Moo 6, instead of putting dolls into a wooden boat and floating the boat in the sea, villagers put the dolls on a big tray and perform the ceremony in a field. The tray is left in the field out of respect for the spirit of the field.

\section{The Application of Local Wisdom to Tambon Bangkhunsai's Master Plan}

The People Research and Development (PR\&D) method facilitated local community members becoming researchers themselves. During the research process, local researchers went through the following steps: collecting data, analyzing data, designing the project plan, conducting public consultation on the project plan, putting the plan into action, and evaluating and monitoring the plan. The PR\&D approach enabled villagers to realize benefits from their 
local wisdom. This point is reflected in the Tambon Bangkhunsai Master Plan, which was the major outcome of the PR\&D process. This plan was called a Community Living Plan, and its goals concentrated on environmental protection and community development. This plan was founded on three principles: ensuring an environmentally friendly ecological system, promoting a social system in which members of the society learn from their experiences and local wisdom, and creating a sustainable economic system that provides sufficiency for the members of the community.

The master plan refers to four main systems: a natural resources management system, a community enterprise management system, a public health management system, and a capital management system to support the principles of the plan. The master plan prioritized activities in each system for implementation in 2004 as follows:

1) Three groups were organized under the natural resources management system: a group to promote learning about shellfish collecting, a coastal resources conservation group, and an eco-tourism group.

2) Five groups were organized under the community enterprise management system: a seafood processing group, a household goods production group, a local product marketing management group, a foodhandlers group, and a boathandlers group.

3) Two groups were organized under the public health management system: a group to promote natural agricultural practices and a group to grow plants used as herbal medicines.
4) One group was organized under the capital management system to create a savings fund for Tambon Bangkhunsai.

All four systems reflect the utilization of local wisdom in order to promote peaceful living with nature. The application of local wisdom in the Community Living Plan is described below:

1) The group for learning about shellfish collection was led by men who were good at collecting shellfish. They wanted to transfer their knowledge to the younger generation. They set up this group to give their knowledge not only to local young people but also to others from nearby communities as well as to tourists who might visit on field trips to this area. It was anticipated that students and visitors would realize the importance of local shellfish harvesting methods that do not destroy the natural resources and the environment.

2) The coastal resources conservation group was based on the older group created in 1992. Local wisdom in terms of living together is central to this group. The benefit of the original group was quite clear, and so Bangkhunsai's community decided to keep this group in their plan. More importantly, this group was now expanded in term of its activities and members.

3) As mentioned above, after sharing their experiences with people from Tambon Kaowkram, the people of Bangkhunsai developed their own plan based on Kaowkram's community plan. Kaowkram's community plan featured three main activities: an eco-tourism group, a foodhandlers group, and a boathandlers group. This plan enabled the Kaowkram community to use its resources for a long period of time. Ispired be the Kaowkram plan, the villagers of Bangkhunsai adopted 
the idea of using coastal resources to promote eco-tourism in addition to collecting shellfish. The eco-tourism group was intended to introduce tourists to the local method of collecting shellfish. They also anticipated that the foodhandlers group and the boathandlers group will benefit from the activities of the eco-tourism group in terms of selling their products and renting boats.

4) The seafood processing group was created out of a desire to promote the use of local wisdom in processing local seafoods. The group to promote natural agricultural practices arose out of the PR\&D process as people learned to compare traditional and current agricultural practices. Traditionally, farmers did not use commercial fertilizers or pesticides. As a result, pesticide residues were not left in the field. The farmers realized that commercial pesticides were having a negative impact on the environment and decided to reinstitute the traditional practices on their farms.

5) The medicinal plants group also came out of the PR\&D process. People learned that the elder of Bangkhunsai used their local wisdom in their daily life in terms of using herbs to make foods and medicines. The household goods production group wanted to produce simple household items such as soap and shampoo for their families to use in order both to save money and to protect their health.

\section{Conclusion}

Phongphit and Nantasuwan (2002a, $2002 \mathrm{~b}$ ) divided the application of local wisdom at the present time into four methods: the conservation method, the recovery method, the adaptation method, and the innovation method. They also explained the characteristic of each method as follows: The conservation method means to preserve local wisdom in the traditional way. The recovery method means to recover local wisdom. The adaptation method means to modify local wisdom so that it applies to the present situation. The innovation method means to invent new local wisdom from existing related knowledge.

All four forms of the application of local wisdom as described by Phongphit and Nantasuwan are found in Tambon Bangkhunsai. The conservation method is evident in the gear and methods used to collect clams and other shellfish in Tambon Bangkhunsai and in the Boon Tai Kan ceremony. The recovery method can be witnessed in the activities of the group to promote learning about traditional shellfish collection, the seafood processing group, and the group to promote natural agricultural practices. The adaptation method can be seen in the activities of the coastal resources conservation group, the eco-tourism group, and the medicinal plants group. Finally, the innovation method is apprent in the activities of the foodhandlers group, the boathandlers group, and the group to produce household goods production group.

These four forms of applying local wisdom in Tambon Bangkhunsai's master plan show that (1) there are many types of local wisdom in Tambon Bangkhunsai, (2) local wisdom found in this tambon is useful for promoting environmental protection, and (3) the PR\&D method can not only discover local wisdom but also help local people to apply local wisdom to develop their community.

The case of Tambon Bangkhunsai suggests not only that local wisdom is central to people's way of life but also that 
it involves ethics and moral values. Local wisdom in Bangkhunsai can be observed in the traditional ways of life, such as occupations, relationships within communities, and spiritual beliefs and practices, and serves to promote an honest, fair, and sustainable use of natural resources. For this reason, development policies should encourage local people to maintain, enrich, and articulate their traditional wisdom and suggest that they apply it to the management of local resources and economic development.

\section{References}

Bruntland Commission (World Commission on Environment and Development). 1987. Our Common Future. Oxford: Oxford University Press.

Na Talang, Ekavit. 2001. Local Wisdom in the Process and Adaptation of Thai People. $2^{\text {nd }}$ ed. Bangkok: Amarin.

Phongphit, Seri, and Wichit Nantasuwan. 2002a. Master Community Plan: People Research and Development. Bangkok: Charoenwit.

Phongphit, Seri, and Wichit Nantasuwan. 2002b. The Learning Process to Sustainable Development. Bangkok: Charoenwit. 